\title{
Effect of INTERACT on Promoting Nursing Staff's Self-Efficacy Leading to a Reduction of Rehospitalizations from Short-Stay Care
}

\author{
Carmen U. Potter \\ Chamberlain University, Chamberlain College of Nursing, St. Louis, USA \\ Email: carmenballardpotter@gmail.com
}

How to cite this paper: Potter, C.U. (2019) Effect of INTERACT on Promoting Nursing Staff's Self-Efficacy Leading to a Reduction of Rehospitalizations from Short-Stay Care. Open Journal of Nursing, 9, 835-854. https://doi.org/10.4236/ojn.2019.98063

Received: June 7, 2019

Accepted: August 18, 2019

Published: August 21, 2019

Copyright $\odot 2019$ by author(s) and Scientific Research Publishing Inc. This work is licensed under the Creative Commons Attribution International License (CC BY 4.0).

http://creativecommons.org/licenses/by/4.0/ (c) (i) Open Access

\begin{abstract}
One in four clients discharged from an acute care facility to a skilled nursing facility (SNF) required readmission to the hospital within 30 days. Neuman, Wirtalla \& Werner believe that two-third of those readmissions are avoidable. Reducing the frequency of rehospitalization from short-stay care is essential for two primary reasons: 1) Clients are exposed to hospital-acquired infections that lead to increased comorbidities, and 2) potentially avoidable hospitalization will decrease the amount of funding distributed by Medicare. The setting for the proposed change initiative was a for-profit, nondenominational SNF in Missouri. Of the 120 beds, 16 were devoted to short-stay care. The convenience sample included four registered nurses and eight licensed practical nurses who had agreed to participate in the pilot. The purposive sample included short-stay clients. Interventions implemented at the pilot skilled nursing facility are components of the validated INTERACT quality improvement program. INTERACT (Appendix A) is comprised of several tools designed to assist and guide front-line staff in early identification, assessment, communication, and documentation about acute changes in client condition. Measured results examined the effectiveness of the proposed intervention. The outcome being assessed in the project was the number of avoidable hospital admissions after implementation of the INTERACT quality initiative tools. The long-term objective for the pilot was a $2 \%$ decrease in client rehospitalizations from the short-care unit during the eight weeks of practice implementation. The clinical question for the proposed practicum project was, "For the nursing staff on a short-term rehab unit, does the implementation of an evidence-based patient evaluation tool, INTERACT lead to a reduction in avoidable hospital admissions?".
\end{abstract}




\section{Keywords}

Rehospitalization, INTERACT, Nursing Home, Quality Improvement

\section{Introduction}

Reducing hospital-acquired conditions and decreasing the number of avoidable rehospitalization are targeted goals of federal health care reform. Vulnerable populations being cared for in skilled nursing facilities (SNF) are often subjected to unnecessary emergency room visits and rehospitalizations. Not only do these actions play a part in healthcare costs inflation, hospital-acquired complications and increased morbidity and mortality rates occur because of avoidable visits to an acute care facility. According to Ouslander, Bonner, Herndon, and Shutes, Medicare and Medicaid may save billions of dollars if unnecessary hospital admissions decrease over the next several years (2014) [1].

Interventions to Reduce Acute Care Transfer (INTERACT) is a quality initiative implemented by many skilled nursing facilities in the United States, Canada, the United Kingdom, and Singapore. Consistent use of the program has been associated with a $24 \%$ reduction in rehospitalizations of nursing home clients over a six-month period [1] [2]. The purpose of the proposed clinical practice change process was to determine if implementing components of the INTERACT program at the SNF would reduce unnecessary rehospitalizations of clients from the short-stay care unit. The project proposal provides an overview of how INTERACT is used to successfully decrease unessential rehospitalizations. Information on the significance of the problem as it relates to a higher than the national percentage of rehospitalizations associated with not using a quality program such as INTERACT is presented. Practice recommendations and the plan to implement the proposed change process are discussed with the goal being preventing unnecessary hospitalizations when safe to do so [3].

\section{Significance of the Practice Problem}

A needs assessment was conducted at the skilled nursing facility. The administration reported the facility has a higher percentage of rehospitalizations from short-care stay than the national average: $26.7 \%$ compared to $21.1 \%$ nationally (Figure 1 ). Knowing that distribution of funds by Medicare is determined by the facility's rehospitalization rate and level of improvement, the skilled nursing facility's leaders sought a quality change process that will decrease the percentage of hospitalizations. Leadership focused on reducing unnecessary rehospitalizations from short-stay care for primarily two reasons: 1) Clients are exposed to hospital-acquired infections that lead to increased comorbidities, and, 2) avoidable rehospitalizations will decrease the amount of funding distributed by Medicare.

Centers for Medicare and Medicaid Services (CMS) issued the final rule for 


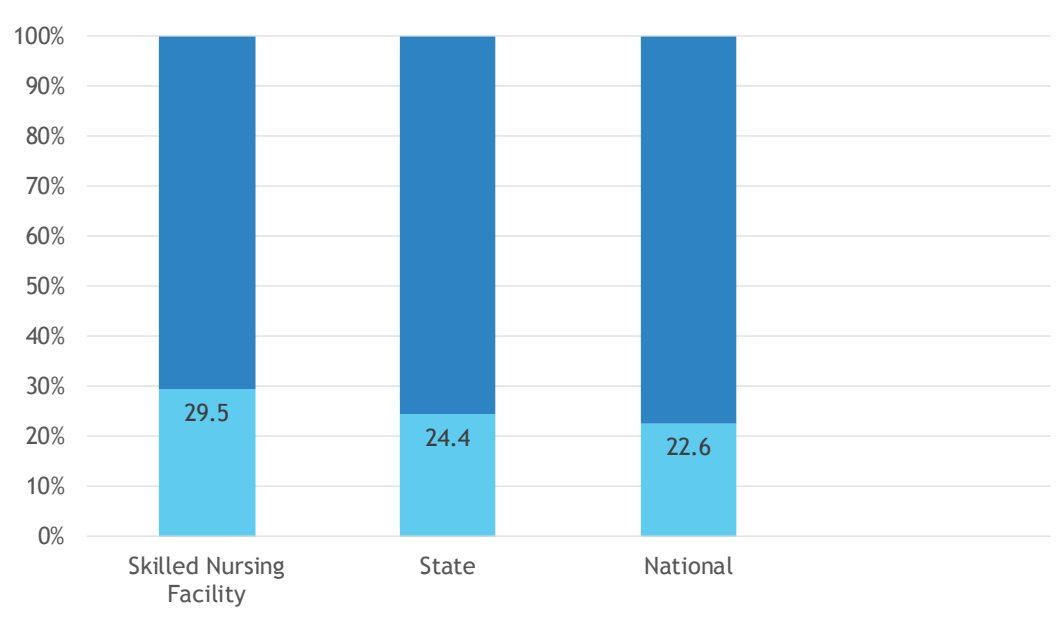

Figure 1. Percentage of short-stay care clients rehospitalized after a nursing home admission (2015).

2016 Medicare skilled nursing facility payment rates. Components of the final rule includes value-based purchasing (VBP) provisions for skilled nursing facilities, based on a hospital readmission measure, set out the 30-day SNF allcause/all-condition hospital readmission measure and adopt that measure for the new SNF value-based purchasing program.

The VBP plans established a $2 \%$ withhold to SNF Part A payments that can be partially earned back based on a SNF's rehospitalization rate and level of improvement. This measure is claim-based, requiring no additional data collection or submission burden for SNFs. The measure is based on 12 months of data compiled by CMS [4].

Researchers that study avoidable hospitalizations among the nursing home population use various definitions and conditions that are potentially avoidable and could be treated at the skilled nursing facility. This is feasible if the nursing staff is skilled in providing care and conduct reliable and accurate assessments. Polniaszek, Walsh \& Weiner [5] prepared a report for the U.S. Department of Health \& Human Services discussing the background and options related to hospitalizations of nursing home clients.

Avoidable hospitalizations are generally grouped into three clinical categories. Preventable but requiring hospitalization, once it occurs, is related to a condition that may not have transpired if high-quality care had been provided by nursing staff and other healthcare providers. It usually leads to hospitalization. An example is the septic resident. Sepsis often occurs when nursing staff do not recognize an infection before it worsens. Septic patients should always be transferred to the hospital for life-threatening conditions.

A second category is preventable but discretionary hospitalization once it occurs. Skilled nurses supported by available and competent healthcare providers sometimes manage conditions at the skilled nursing facility. The condition may have been preventable or may have developed despite high-quality care. Pneu- 
monia is the most common indicator associated with potentially avoidable hospitalization.

The third category of avoidable hospitalization is futile care. For the client near the end of life, futile care neither improves or prolongs quality of life. It is essential that advance care documents be in place. It is of equal importance for family members and staff have a clear understanding of the intent of such documents for the client near end of life to avoid an unnecessary hospitalization [5].

Reducing avoidable rehospitalizations of nursing home clients is a priority area of interest addressed by the CMS. Primary concerns of CMS are the quality of care for nursing home clients and costs perspectives associated with unnecessary rehospitalizations [6] [7]. In some cases, rehospitalization rates were higher for nursing home clients than the geriatric population in the community. Approximately $\$ 972$ million was spent on avoidable rehospitalizations from skilled nursing facilities in New York alone [6].

Skilled nursing facilities are facing financial penalties for unnecessary rehospitalizations of Medicare clients. Facility leadership will need to reevaluate their ability to provide safe quality care to clients with complex needs [8]. Determining needs for additional training of nursing staff is essential for staff to care for the frailer client with comorbidities. Along with this, leadership of the skilled nursing facilities will need to avoid accepting clients with physical and mental needs the nursing staff is not familiar with until training and education are provided. There are many factors and incentives that influence the decision to hospitalize long-term care clients that are considered by nursing staff (Figure 2) when making the decision to transfer the client to the hospital [3].

Lamb, Tappen, Diaz, Herndon \& Ouslander conducted a mixed method qualitative and quantitative study of skilled nursing facilities nursing staffs' understandings of avoidable hospital transfers [9]. The staff had implemented INTERACT as a quality improvement. After the completion of the pilot, nursing staff rated $76 \%$ of the transfers were not avoidable. Cited reasons included acute condition change in the client, family insistence, and order for transfer from the healthcare provider. Nursing staff pointed out these same reasons as causes for avoidable rehospitalizations [9].

Policies in the Affordable Care Act (ACA) have created financial rewards to skilled nursing facilities which are able to provide appropriate care to the client who develops acute changes in condition without transferring to the hospital [2]. CMS has identified six condition categories that contribute approximately $80 \%$ of avoidable hospitalizations [4]:

- Pneumonia

- Dehydration

- Congestive heart failure

- Urinary tract infection

- Skin ulcers, cellulitis, and

- Chronic obstructive pulmonary disease, asthma 


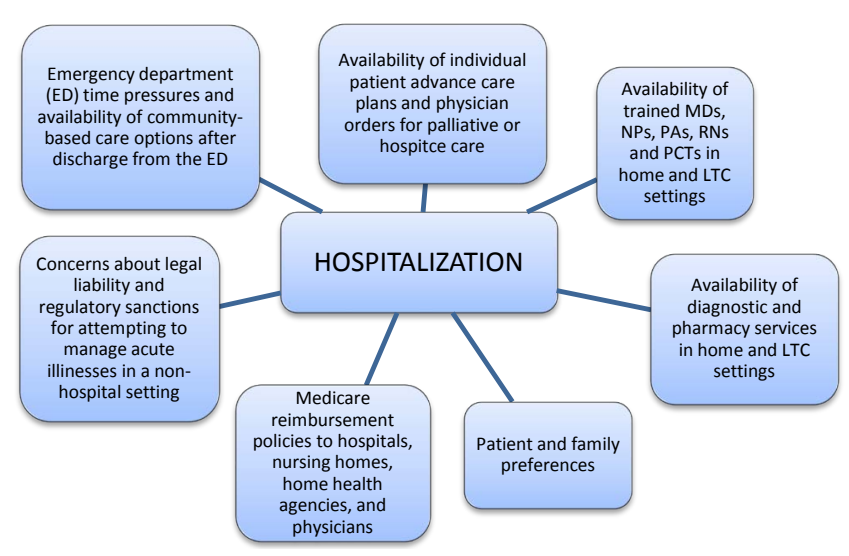

Figure 2. Factors and incentives that influence the decision to hospitalize long-term care patients [3].

This is not to say nursing staff should avoid rehospitalization of all clients. Such decisions may result in unintended outcomes such as deterioration in condition leading to death [9]. Skilled nursing facility staff have to demonstrate above average assessment skills to prevent unnecessary rehospitalizations. Nursing staff must perform ongoing assessments with appropriate communication of the assessment findings to healthcare providers as acute changes of clients are discovered. Assessments and dissemination of the findings to the healthcare provider must be performed professionally with the use of validated tools.

The ACA requires CMS to establish regulations for quality assurance performance improvement (QAPI) for skilled nursing facilities. Section 6102 of the Affordable Care Act also requires CMS to provide "technical assistance, tools and resources for providers promulgating the new regulation" [1]. INTERACT may provide skilled nursing facilities a way to reduce hospital readmissions that are not necessary. Three general characteristics have been noted in facilities that implemented INTERACT successfully: leadership support, engagement of nursing staff and a site champion, and a culture enthusiastic about quality improvement [1].

Improperly trained nursing staff can lead to negative client outcomes resulting from unnecessary rehospitalizations. More than 2 million skilled nursing facility clients are transferred to the emergency room, and almost half are hospitalized. Rehospitalizations interfere with client-established relationships and care patterns at the skilled nursing facility. Added risks include the occurrence of adverse events, such as falls, skin ulcers, and hospital-acquired infections [2].

Another problem resulting from unnecessary rehospitalizations is undesirable financial consequences as well as sanctions by the regulatory agency. Decisions that are driven by reimbursement rates and regulatory policies often override client and family preferences. Complying with CMS regulation and still maintain expected profits are areas of importance to corporate stakeholders. This could present a barrier in the adoption of new validated strategies that can be imple- 
mented to reduce avoidable rehospitalizations [2] [8].

\section{Theoretical Frameworks}

McEwen identified Benner's Model of Skill Acquisition in nursing as helpful as it defines the importance of retaining and rewarding clinical expertise in practice settings [10]. Using Benner's Model as a conceptual framework, continued studies have been done to determine the achievement of the nurse in decision-making skills. It is also common to utilize Benner's applicability in the development of procedures and protocols for orientations of new nurses and new graduates [10]. Benner's primary philosophical argument is that skill achievements are quicker and safer when experience-based and the nurse has a firm educational foundation. Nursing skills and application of those skills allow the nurse to focus on establishing skilled nursing interventions within the scope of practice while using effective critical thinking skills within the practice setting [11].

Benner's model explains that as a nurse advances through the levels of novice to expert, changes are mirrored in three aspects of skill performance. One, the individual shifts from depending on abstract principles to the use of past concrete experiences. Secondly, there is a change in the learner's outlook of the situation, where it is seen less as distinct equal pieces and more as a whole where only certain parts are significant. Lastly, the individual changes from an outside observer of the situation to an engaged performer [12].

Novice or beginner nurses are not able to practice safely related to lack of experience in the area they are expected to perform. They lack experience, knowledge, and training and are not able to conduct a high-quality condition assessment. Novice nurses do not communicate client information in an effective manner to the healthcare provider [11].

Advanced beginner nurses are developing knowledge. They continue to require support as they begin to assess clients safely and effectively. Advanced beginner nurses still take cues from the more experienced nurse [13].

Competent nurses demonstrate efficiency and are confident in their abilities to provide safe care to the client. Competent nurses have been on the job 2 - 3 years. Problem solving becomes easier and appropriate decisions are made in the client's best interests [13].

The proficient nurse provides holistic care and has learned from previous experiences. Proficient nurses establish care priorities and manage time well. They have developed intuition and demonstrate deep understanding of wholeness. They are analytical and provide high-quality safe client care [13].

According to Alligood, Benner describes clinical nursing practice by using an interpretive phenomenological approach [14]. Dr. Benner maintains that there are excellence and power in clinical nursing practice that can be visible through articulation research. In addition, Benner defines skill and skilled practice to mean implementing skilled nursing interventions and clinical judgment skills in actual clinical situation [11] [15]. Skilled activities are often thought of as less 
than intellectual but these activities are dependent on embodied knowing. Benner believes that competency assessment should be established in actual practice, under pressure, and over time, and related to patient outcomes [11]. Benner's philosophy easily provides the framework for a hospital-based quality improvement innovation study.

The Joanna Briggs Institute (JBI) Model of Evidence-based Healthcare (Figure 3) provides a framework for evidence-based practice (EBP) set in healthcare evidence. The model defines EBP as "clinical decision-making that considers the best available evidence; the context in which the care is delivered; client preferences; and the professional judgment of the health professional" [16]. The JBI model conceptualizes the process of improving health outcomes through the understanding and translation of knowledge into the clinical arena. The center of the JBI model focuses on feasibility of the proposed intervention, appropriateness of the intervention to the situation, meaningfulness to the group providing them with a positive experience, and effectiveness of the intervention in achieving the desired outcomes [16].

The model acknowledges that innovative and new information occurs with both primary and secondary research. Systematic reviews are essential to identify knowledge gaps in clinical practice. Research does not always exist for every intervention or process. Healthcare providers and other clinicians must still make care decisions and continue searching for evidence to generate safe decision-making.

Evidence implementation is a purposeful set of activities developed to engage key stakeholders. Presenting research evidence to decision makers is conducive to sustain ability of quality improvements [16].

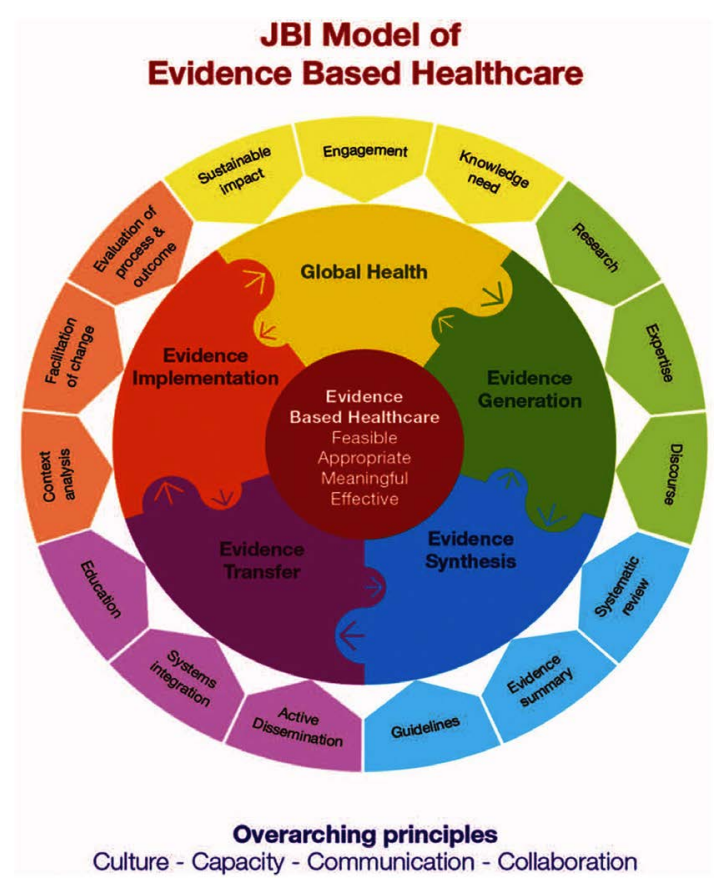

Figure 3. Joanna briggs institute model of evidence-based healthcare. 


\section{Synthesis of Literature}

A literature search was conducted using key terms "rehospitalization, nursing home, INTERACT, and quality improvement". Papers published from 2009 to 2016 were included and served as the foundation in establishing whether the use of structured tools in the skilled nursing facility reduced potentially preventable hospitalizations. Of the 61 articles located, 14 were specific to the area of interest. Levels of evidence were assigned to each study. The synthesis of literature includes nine systematic reviews/meta-analysis and five primary research studies. Integrative/summary articles are not included in the synthesis. It was determined that available evidence recommends training of nursing home staff and structured tools used consistently use may decrease unnecessary hospital admissions from skilled nursing facilities. Research also suggests barriers such as lack of enthusiasm or support for the change initiative may threaten validity and reliability of data collection. Nine of the fourteen peer-reviewed journal articles are systematic reviews. One is a randomized control study that targets the use of standardized validated tools such as the ones available in the INTERACT quality initiative program. All articles conclude that education and training are needed to manage clients' deteriorating conditions. Secondly, communication problems between the skill nursing facility staff and healthcare providers must be resolved to avoid unnecessary rehospitalizations. The authors also agree further research is needed. Generally, most authors agree that determining gaps between local practice and best (evidence-base) practices is the first step toward reducing readmissions (Appendix B).

The remaining five articles are pilot studies conducted at skilled nursing facilities. All studies used INTERACT as a strategy to reduce client hospital readmissions. Education and nursing staff support were common themes identified (Appendix C). Staff confidence is essential for a quality initiative program to be successful. INTERACT tools can play an important role in assisting skilled nursing facilities to improve quality of care and contribute to CMS efforts to reduce morbidity and costs associated with rehospitalization. However, a need is indicated for further evaluation of INTERACT interventions in more controlled trials. They are needed to provide more reliable evidence to skilled nursing facility leadership and therefore promote a better understanding of such strategies.

The literature synthesis revealed similar conclusions from both systematic and pilot research studies. Formal educational activities and consistency in practice influence rehospitalization rates from skilled nursing facilities. "Such readmissions cost the U.S. healthcare system approximately \$17 billion annually" [17].

\section{Methods and Data}

The setting for the proposed practice change was a for-profit corporation, non-denominational skilled nursing facility located in Missouri, United States. The capacity of the SNF was 120 beds of which 16 were devoted to short-stay care. The convenience sample consisted of four registered nurses (RNs) and 
eight licensed practical nurses (LPNs) who had agreed to participate in the pilot and worked varying shifts. The purposive sample for data collection included short-stay care clients at the skilled nursing facility. Protection of human rights was maintained throughout the project.

The interventions implemented at the skilled nursing facility were components of INTERACT. INTERACT decision support tools included Stop and Watch lanyard cards (Appendix D) Care Paths, Acute Change in Condition file cards (Appendix E), Change in Condition Progress Note, and SBAR Communication Tool. The Director of Nursing wanted to acclimate the nursing staff slowly to INTERACT components to facilitate more of a buy-in from the nurses.

Comparison of pre- and post-hospitalizations from short-care stay was conducted after implementation of the INTERACT program. There was no standardized method in place to assist nursing staff with client evaluation or in giving the condition information to the healthcare provider. The comparison for this project was pre- and post-intervention data collected from CMS. The nurse manager reported that a standardized evaluation and handoff tool was not used by nursing staff and has led to high percentages of hospitalizations from the short-care unit. The evaluation instruments for this project also consisted of pre-and post-implementation survey 11 item 5-point Likert-type scale where five indicated the participant strongly agreed and one indicated strongly disagree. This formative tool was used to establish participants' confidence in knowledge of INTERACT and their confidence in recognizing changes in the client condition. The summative evaluation instrument was the same survey and data analysis. The SPSS program was utilized for data analysis. A paired t-test was applied to evaluate rehospitalizations pre- and post-implementation of INTERACT using the Acute Care Transfer Log worksheet.

The assessed outcome was the number of avoidable hospital admissions after implementation of the INTERACT quality initiative components. The long-term objective for the pilot was a $2 \%$ decrease in client re-hospitalizations from the short-care unit during the eight weeks of practice implementation.

\section{Analysis and Results}

The effect on a number of rehospitalizations over three periods: the mean rate of rehospitalizations at the end of November 2016 was 66\%, during February and March 2017 was 16\% (pre-implementation), and during April and May 2017 was $60.5 \%$ (post-implementation) (Figure 4). Agency management explained that some of the differences among the three rates are the differences in acuity of residents and in family preferences for the residents. Client care acuity was considerably lower in February and May 2017. Results indicated at least a 5.5\% reduction in rehospitalizations was achieved from November 2016 compared to April May 2017 when client acuity levels were higher.

Twelve licensed nursing personnel participated in both phases of the project with four registered nurses and eight licensed practical nurses. Based on data, there were no statistically significant differences on any of the items used to 
evaluate the INTERACT program.

Although there were no statistically significant differences, there were increases in the mean scores on the items related to Table 1.

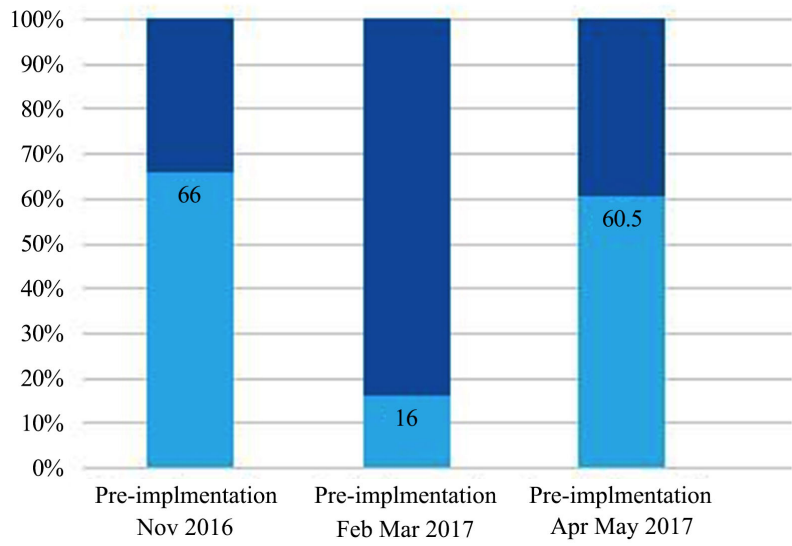

Figure 4. Effect of INTERACT on rehospitalizations.

Table 1. T test results for each item and total score on instrument used to evaluate the interact program.

\begin{tabular}{|c|c|c|c|c|c|}
\hline & Phase & Mean & Std. Deviation & $\mathrm{t}$ & Sig. (2-tailed) \\
\hline \multirow{2}{*}{$\begin{array}{c}\text { Confident } \\
\text { Communicating Conditions }\end{array}$} & Pre-Implementation & 4.67 & 0.492 & 0.000 & 1.000 \\
\hline & Post-Implementation & 4.67 & 0.492 & & \\
\hline \multirow{2}{*}{$\begin{array}{c}\text { Confident Reporting } \\
\text { Changes }\end{array}$} & Pre-Implementation & 4.58 & 0.515 & -0.842 & 0.409 \\
\hline & Post-Implementation & 4.75 & 0.452 & & \\
\hline \multirow{2}{*}{$\begin{array}{c}\text { Comfortable } \\
\text { Suggesting Changes }\end{array}$} & Pre-Implementation & 4.50 & 0.674 & 0.000 & 1.000 \\
\hline & Post-Implementation & 4.50 & 0.522 & & \\
\hline \multirow{2}{*}{$\begin{array}{l}\text { Comfortable Knowing } \\
\text { What to Do }\end{array}$} & Pre-Implementation & 4.25 & 0.754 & -0.632 & 0.534 \\
\hline & Post-Implementation & 4.42 & 0.515 & & \\
\hline \multirow{2}{*}{$\begin{array}{c}\text { Comfortable } \\
\text { Prioritizing Needs }\end{array}$} & Pre-Implementation & 3.75 & 1.357 & -1.593 & 0.125 \\
\hline & Post-Implementation & 4.50 & 0.905 & & \\
\hline \multirow{2}{*}{$\begin{array}{l}\text { Can Use Knowledge } \\
\text { to Prevent Harm }\end{array}$} & Pre-Implementation & 4.50 & 0.674 & 0.572 & 0.573 \\
\hline & Post-Implementation & 4.25 & 1.357 & & \\
\hline \multirow{2}{*}{$\begin{array}{c}\text { Ability } \\
\text { to Recognize Changes }\end{array}$} & Pre-Implementation & 4.17 & 0.937 & -0.226 & 0.823 \\
\hline & Post-Implementation & 4.25 & 0.866 & & \\
\hline \multirow{2}{*}{ Realistic Job Expectations } & Pre-Implementation & 3.75 & 1.215 & -0.609 & 0.549 \\
\hline & Post-Implementation & 4.00 & 0.739 & & \\
\hline \multirow{2}{*}{$\begin{array}{l}\text { Satisfaction with } \\
\text { Responsibility }\end{array}$} & Pre-Implementation & 3.42 & 1.505 & -0.612 & 0.547 \\
\hline & Post-Implementation & 3.75 & 1.138 & & \\
\hline \multirow{2}{*}{ INTERACT Is Helpful } & Pre-Implementation & 4.08 & 0.793 & -1.113 & 0.278 \\
\hline & Post-Implementation & 4.42 & 0.669 & & \\
\hline \multirow{2}{*}{$\begin{array}{c}\text { New Processes } \\
\text { Supported by Management }\end{array}$} & Pre-Implementation & 4.42 & 0.669 & 0.632 & 0.534 \\
\hline & Post-Implementation & 4.25 & 0.622 & & \\
\hline \multirow{2}{*}{ Total Score } & Pre-Implementation & 42.0000 & 4.41073 & -0.787 & 0.440 \\
\hline & Post-Implementation & 43.3333 & 3.86907 & & \\
\hline
\end{tabular}


- Confidence in Reporting Changes,

- Comfortable Knowing What to Do,

- Comfortable Prioritizing Needs,

- Ability to Recognize Changes,

- Realistic Job Expectations,

- Satisfaction with Responsibility, and INTERACT Was Helpful as well as the total mean score on the instrument, and,

- INTERACT Was Helpful as well as the total mean score on the instrument. The only items where there was a decrease in mean score were: Can Use Knowledge to Prevent Harm and New Processes Supported by Management. There was no change in mean scores on two items: Confident Communicating Conditions and Comfortable Suggesting Changes.

Two things are well known in writing about survey items. One is social desirability answers: it is difficult to reveal weaknesses. Secondly, there is the response set bias where participants put one answer for all items without reading. The statistician believed the first is more likely with this survey since some items required reverse scoring.

\section{Discussion and Conclusion}

Current literature supports the need for the proposed project for evaluation a quality initiative to implement all or some of the INTERACT tools and strategies for decreasing potentially unnecessary hospital transfers for nursing home clients. Consistent and structured communication improves nursing staff's ability to observe, report, act, and communicate information appropriately to the healthcare provider to avoid hospitalization [3]. The search of literature also revealed that specific chronic disease processes such as pneumonia, hypertension, diabetes mellitus, and congestive heart failure often result in potentially avoidable hospital admissions [3]. Evidence does support implementation of tools and strategies to communicate in a structured manner using a tool such as SBAR to achieve beneficial results [18].

The significance of the problem of higher than state and national percentages as it relates to client transfers to hospitals is related to a nonstandardized process. Validated tools available from the INTERACT quality initiative program may reduce avoidable rehospitalizations from skilled nursing facilities. Establishing and consistent use of a standardized set of tools at the practicum facility may improve quality of care, reduce avoidable hospitalization CMS scores, and decrease client exposure to hospital-acquired infections. An improvement in the reduction of rehospitalizations scores determines reimbursement rate for skilled nursing facility payments as provision set by the Affordable Care Act. Implementation of the INTERACT program that is in the practicum facility will meet the needs and requirements of the facility's leadership as well as nursing staff at the microlevel of the organization.

INTERACT is a validated quality improvement program that provides struc- 
tured information and tools that may be used for client assessment that can be relayed to the healthcare provider in a structured SBAR format. The INTERACT quality improvement program is designed to assist front-line staff in early identification, assessment, communication, and documentation acute changes in client condition. Components include clinical and educational tools and strategies for use in everyday practice in skilled nursing facilities. Skilled nursing facilities across the country have implemented the INTERACT quality improvement program. Many facilities have significantly reduced avoidable hospitalizations using these resources [1] [2].

\section{Acknowledgements}

I would like to express my great appreciation to Martha A. Spies, Ph.D., MSN, RN for her valuable and constructive suggestions during the planning and development of this clinical research work. My grateful thanks are also extended to Dr. Spies for compiling data and interpreting statistics for the project. Her willingness to give her time so generously is deeply appreciated.

\section{Conflicts of Interest}

The authors declare no conflicts of interest regarding the publication of this paper.

\section{References}

[1] Ouslander, J., Bonner, A., Herndon, L. and Shutes, J. (2014) The Interact Quality Improvement Program: An Overview for Medical Directors and Primary Care Clinicians in Long-Term Care. Journal of American Medical Directors Association, 15, 162-170. https://doi.org/10.1016/j.jamda.2013.12.005

[2] Toles, M., Young, H.M. and Ouslander, J. (2012) Improving Care Transitions in Nursing Homes. Generations, 36, 78-85.

[3] Maslow, K. and Ouslander, J. (2012) Measurement of Potentially Preventable Hospitalizations.

http://www.ltqa.org/wp-content/themes/ltqaMain/custom/images/PreventableHosp italizations_021512_2.pdf

[4] Boccuti, C. and Casillas, G. (2017) Aiming for Fewer Hospital U-Turns: The Medicare Hospital Readmission Reduction Program.

http://files.kff.org/attachment/Issue-Brief-Fewer-Hospital-U-turns-The-MedicareHospital-Readmission-Reduction-Program

[5] Polniaszek, S., Walsh, E. and Weiner, J. (2011) Hospitalizations of Nursing Home. https://aspe.hhs.gov/sites/default/files/pdf/76296/NHResHosp.pdf

[6] O’Neil, B., Parkinson, L., Dwyer, T. and Reid-Searl, K. (2015) Nursing Home Nurses' Perceptions of Emergency Transfers from Nursing Homes to Hospital: A Review of Qualitative Studies Using Systematic Methods. Geriatric Nursing, 36, 423-430. https://doi.org/10.1016/j.gerinurse.2015.06.001

[7] Rantz, M., Flesner, M., Franklin, J., Galambos, C., Pudlowski, J., Pritchett, A., Alexander, A. and Lueckenotte, A. (2015) Better Care, Better Quality. Journal of Nursing Care Quality, 30, 290-297. https://doi.org/10.1097/NCQ.0000000000000145

[8] Feldkamp, J. (2014) Push to Avoid Rehospitalization Has Unintended Outcomes. 
Caring for the Ages, 15, 7. https://doi.org/10.1016/j.carage.2014.08.010

[9] Lamb, G., Tappen, R., Diaz, S., Herndon, L. and Ouslander, J. (2011) Avoidability of Hospital Transfers of Nursing Home Residents: Perspectives of Frontline Staff. Journal of American Geriatrics Society, 59, 1665-1672. https://doi.org/10.1111/j.1532-5415.2011.03556.x

[10] McEwen, M. (2011) Theoretical Basis for Nursing. 3rd Edition, Lippincott Williams \& Wilkins, Philadelphia.

[11] Benner, P. (2001) From Novice to Expert: Excellence and Power in Clinical Nursing Practice, Commemorative Edition. Prentice-Hall, Upper Saddle River.

[12] Benner, P. (1984) From Novice to Expert: Excellence and Power in Clinical Nursing Practice. Addison-Wesley, Menlo Park, 13-34.

https://doi.org/10.1097/00000446-198412000-00025

http://www.health.nsw.gov.au/nursing/projects/Documents/novice-expert-benner.p df

[13] Alligood, M. (2014) Nursing Theorists and Their Work. 8th Edition, Mosby, St. Louis.

[14] Brkczynski, K. (2014) Nursing Theorists and Their Work. 8th Edition, Mosby, St. Louis.

[15] Jordan, Z., Lockwood, C., Munn, Z. and Aromataris, E. (2019) The Updated Joanna Briggs Institute of Evidence-Based Healthcare. International Journal of Evidence-Based Healthcare, 17, 58-71. https://doi.org/10.1097/XEB.0000000000000155

[16] Nelson, J. and Pulley, A. (2015) Transitional Care Can Reduce Hospital Readmissions. American Nurse Today, 10. http://www.medscape.com/viewarticle/844301

[17] Ouslander, J., Lamb, G., Tappen, R., Herndon, L., Diaz, S., Roos, B., Grabowski, D.C. and Bonner, A. (2011) Interventions to Reduce Hospitalizations from Nursing Homes: Evaluation of the INTERACT II Collaborative Quality Improvement Project. Journal of American Geriatrics Society, 59, 745-753. https://doi.org/10.1111/j.1532-5415.2011.03333.x

[18] Centers for Medicare and Medicaid Services (CMS) (2015) Skilled Nursing Facility Readmission Measure (SNFRM) NQF \#2510.

https://www.cms.gov/Medicare/Quality-Initiatives-Patient-Assessment-Instruments /Value-Based-Programs/Other-VBPs/Technical-Report-Supplement.pdf 


\section{Appendix A. INTERACT}

\section{Using the INTERACT Tools In Every Day Care}
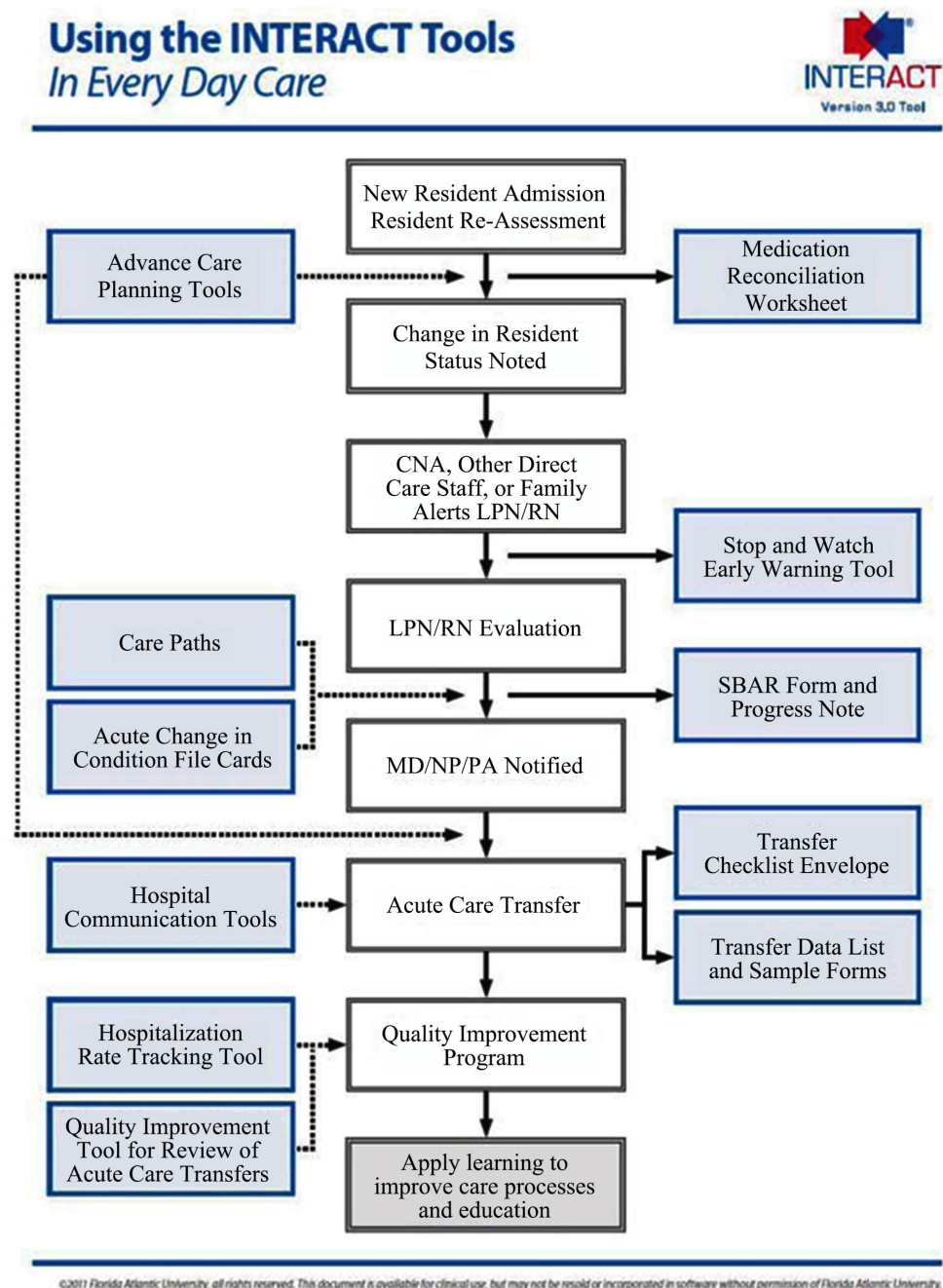

\section{Appendix B. Systematic Reviews}

\begin{tabular}{|c|c|c|c|c|c|c|}
\hline Citation & Question & Search Strategy & $\begin{array}{l}\text { Inclusion/ } \\
\text { Exclusion Criteria }\end{array}$ & $\begin{array}{l}\text { DataExtraction \& } \\
\text { Analysis }\end{array}$ & Key Findings & $\begin{array}{l}\text { Recommendations } \\
\text { \&Implications }\end{array}$ \\
\hline $\begin{array}{l}\text { Laging, Ford, } \\
\text { Bauer \& Nay, } \\
2015\end{array}$ & $\begin{array}{l}\text { Explore the role in } \\
\text { nursing home staff } \\
\text { in decisions to } \\
\text { transfer to hospital }\end{array}$ & $\begin{array}{l}\text { Systematic review; } \\
\text { meta-synthesis; } \\
\text { CINAHL, Embase, } \\
\text { Medline, and } \\
\text { PsycInfo databases } \\
\text { were searched }\end{array}$ & $\begin{array}{l}\text { Qualitative } \\
\text { research papers } \\
\text { published between } \\
\text { January } \\
\text { 1989-Ocotber 2012; } \\
\text { transfers to hospital } \\
\text { from the nursing } \\
\text { home setting }\end{array}$ & $\begin{array}{l}\text { Study categories } \\
\text { were synthesized } \\
\text { on the basis of } \\
\text { similarity in } \\
\text { meaning. The } \\
\text { categories were } \\
\text { then placed into } \\
\text { five synthesized } \\
\text { findings. Each } \\
\text { study was reviewed } \\
\text { and re-read. } \\
\text { Author findings } \\
\text { were extracted and } \\
\text { findings supported } \\
\text { using the JBI-QARI }\end{array}$ & $\begin{array}{l}\text { Nursing home staff } \\
\text { members play a key } \\
\text { role in decision } \\
\text { making at the time } \\
\text { of a client's } \\
\text { deterioration. } \\
\text { Multiple factors } \\
\text { influence decisions } \\
\text { to transfer to } \\
\text { hospital including } \\
\text { an unclear } \\
\text { expectation of the } \\
\text { nursing home role; } \\
\text { limited staffing } \\
\text { capacity; fear of } \\
\text { working outside } \\
\text { their scope of } \\
\text { practice; poor }\end{array}$ & $\begin{array}{l}\text { There is a lack of } \\
\text { consensus regarding } \\
\text { the role of the } \\
\text { nursing home when } \\
\text { a client's condition } \\
\text { deteriorates. } \\
\text { Nursing home staff } \\
\text { would benefit from } \\
\text { a clear } \\
\text { understanding of } \\
\text { their expected } \\
\text { clinical skill set; a } \\
\text { staffing capacity that } \\
\text { allows for the } \\
\text { increased } \\
\text { requirements to } \\
\text { manage clients } \\
\text { on-site, greater }\end{array}$ \\
\hline
\end{tabular}




\begin{tabular}{|c|c|c|c|c|c|c|}
\hline & & & & & $\begin{array}{l}\text { access to } \\
\text { multidisciplinary } \\
\text { support and } \\
\text { difficulties } \\
\text { communicating } \\
\text { with other decision } \\
\text { makers }\end{array}$ & $\begin{array}{l}\text { consistency in } \\
\text { access to outside } \\
\text { resources and } \\
\text { further confidence } \\
\text { and skills to } \\
\text { optimize their role } \\
\text { in client advocacy. } \\
\text { All nursing home } \\
\text { clients (with their } \\
\text { families) should be } \\
\text { encouraged to } \\
\text { identify and } \\
\text { document their end } \\
\text { of life care wishes. }\end{array}$ \\
\hline $\begin{array}{l}\text { Low, Fletcher, } \\
\text { Goodenough, } \\
\text { Jeon, } \\
\text { Etherton-Beer, } \\
\text { McAndrew, } \\
\text { \& Beattie, } 2015\end{array}$ & $\begin{array}{l}\text { What interventions } \\
\text { have been attempted } \\
\text { to change staff } \\
\text { practice to improve } \\
\text { long-term care } \\
\text { resident outcomes? }\end{array}$ & $\begin{array}{l}\text { Systematic review } \\
\text { of interventions } \\
\text { that attempted to } \\
\text { change staff } \\
\text { practice to improve } \\
\text { long-term care } \\
\text { resident outcomes }\end{array}$ & $\begin{array}{l}\text { Randomized } \\
\text { controlled trials } \\
\text { and } \\
\text { quasi-experimental } \\
\text { controlled trials } \\
\text { were included as } \\
\text { recommended by } \\
\text { the EPOC group. }\end{array}$ & $\begin{array}{l}\text { Extracted using } \\
\text { standard forms } \\
\text { based on forms } \\
\text { developed by the } \\
\text { Cochrane Effective } \\
\text { Practice and } \\
\text { Organisation of } \\
\text { Care Group. } \\
\text { Extraction was } \\
\text { conducted by one } \\
\text { researcher and } \\
\text { checked by a } \\
\text { second researcher. }\end{array}$ & $\begin{array}{l}\text { Results support } \\
\text { that using theory to } \\
\text { plan } \\
\text { implementation } \\
\text { strategies will } \\
\text { increase the success } \\
\text { of translating } \\
\text { research into } \\
\text { practice change. } \\
\text { When staff } \\
\text { behavior is not } \\
\text { measured, it is not } \\
\text { clear whether the } \\
\text { program has been } \\
\text { unsuccessful } \\
\text { because of } \\
\text { implementation } \\
\text { error or because } \\
\text { the staff behavior } \\
\text { has changed, but } \\
\text { has not brought } \\
\text { about the desired } \\
\text { improvement in } \\
\text { clients. }\end{array}$ & $\begin{array}{l}\text { Changing staff } \\
\text { practice in nursing } \\
\text { homes is possible } \\
\text { but complex. } \\
\text { Interventionists } \\
\text { should consider } \\
\text { barriers and } \\
\text { feasibility of } \\
\text { program } \\
\text { components to } \\
\text { impact on each } \\
\text { intended outcome. }\end{array}$ \\
\hline $\begin{array}{l}\text { Nelson \& Pulley, } \\
2015\end{array}$ & $\begin{array}{l}\text { State the problem of } \\
\text { readmission rates; } \\
\text { compare transitional } \\
\text { care models; discuss } \\
\text { strategies for } \\
\text { effective transitional } \\
\text { care }\end{array}$ & $\begin{array}{l}\text { Systematic } \\
\text { literature search: } \\
\text { not stated }\end{array}$ & $\begin{array}{l}25 \text { long term care } \\
\text { facilities that } \\
\text { incorporated } \\
\text { INTERACT quality } \\
\text { improvement } \\
\text { program (a } \\
\text { transitional care } \\
\text { model principle) }\end{array}$ & $\begin{array}{l}\text { In } 2014 \\
\text { meta-analysis of } 26 \\
\text { RCTs one research } \\
\text { group for } 30 \text {-day } \\
\text { readmissions were } \\
\text { reduced only by } \\
\text { high intensity } \\
\text { transitional care } \\
\text { model principles }\end{array}$ & $\begin{array}{l}\text { Rates decreased an } \\
\text { average of } 17 \% \text {; } \\
\text { facilities with } \\
\text { greater } \\
\text { commitment and } \\
\text { resources allocated } \\
\text { to model } \\
\text { implementation } \\
\text { saw greater } \\
\text { reductions than } \\
\text { those SNFs with a } \\
\text { minimal } \\
\text { commitment }\end{array}$ & $\begin{array}{l}\text { Transitional care } \\
\text { models are } \\
\text { recommended with } \\
\text { high-risk older } \\
\text { adults to prevent } \\
\text { hospital } \\
\text { readmission. }\end{array}$ \\
\hline $\begin{array}{l}\text { O’Neill, } \\
\text { Parkinson, } \\
\text { Dwyer, \& } \\
\text { Reid-Searl, } \\
2015\end{array}$ & $\begin{array}{l}\text { Describe nursing } \\
\text { home nurses' } \\
\text { perception around } \\
\text { emergency transfers } \\
\text { to hospital. }\end{array}$ & $\begin{array}{l}\text { CINAHL, Health } \\
\text { Source: Nursing } \\
\text { Academic Edition, } \\
\text { MEDLINE, JBI of } \\
\text { Systematic } \\
\text { Reviews; published } \\
\text { studies between } \\
2000 \text { and 2014, } \\
\text { English, }\end{array}$ & $\begin{array}{l}\text { Inclusion: } 7 \\
\text { qualitative studies } \\
\text { \& mixed-method } \\
\text { studies that focus } \\
\text { on } \\
\text { decision-making } \\
\text { processes by nurses } \\
\text { Exclusion: poor } \\
\text { nursing staff }\end{array}$ & $\begin{array}{l}\text { The findings from } \\
\text { each study were } \\
\text { summarized } \\
\text { verbatim and } \\
\text { organized in NVivo } \\
\text { 10. A total of } 92 \\
\text { findings were } \\
\text { extracted and } \\
\text { assigned a }\end{array}$ & $\begin{array}{l}\text { Meta synthesis } 1 \text { : } \\
\text { Nursing home } \\
\text { nurses require } \\
\text { clinical knowledge, } \\
\text { skills, and } \\
\text { resources to assess } \\
\text { and manage the } \\
\text { deteriorating client. } \\
\text { Meta synthesis 2: }\end{array}$ & $\begin{array}{l}\text { Targeted education } \\
\text { for nursing; identify } \\
\text { problems causing } \\
\text { communication } \\
\text { issues; nurses' } \\
\text { perceptions around } \\
\text { perceptions of } \\
\text { hospital transfer } \\
\text { must be sought and }\end{array}$ \\
\hline
\end{tabular}


Graverholt, Forsetlund, \&Jamtvedt, 2014
Renom-Guiteras, The goal of the Uhrenfeldt, Meyer, \& Mann, 2014

$\begin{array}{ll}\text { Maslow } & \text { Search for quality } \\ \text { \&Ouslander, } & \text { measures that have } \\ 2012 & \text { been developed to } \\ & \text { identify potentially } \\ \text { preventable }\end{array}$
systematic review is 1) to provide an overview of the studies dealing with tools for assessing appropriateness of hospital admissions in long term care residents and 2) to describe the published assessment tools in detail, including information about their development and the aspects covered by the tools.

\section{peer-reviewed}

Summarize the effects of interventions to reduce acute hospitalizations from nursing homes

Systematic review of the literature using PubMed and CINAHL was conducted. The search covered 7 languages from January 2000 and December 2012.

performed in
Cochrane Library,
PubMed,
MEDLINE,
EMBASE and ISI
Web of Science

Studies were included if they had studies, assessing a geriatric nursing home study population \& were the total evidence evaluating any type was conducted by of intervention two researchers aimed at reducing individually. acute hospital

admissions.

Systematic reviews,

RCTs, controlled

before-after studies

and interrupted

time series were eligible.

All quantitative studies were

included if any

Twenty-nine articles were assessment tool for study periods appropriateness of between 1991 and hospital and/or emergency department admission of long-term care 2009. Two independent researchers extracted residents was used. study nformation on the characteristics and the assessment tools. Inter-related reliability was not calculated because most information extracted was descriptive.

Focused on U.S.
sources

Inclusion:

Population that is Analysis of quality frail and chronically ill who receive long-term considered

nurses use

persuasive and

targeted

communication

techniques to

manage and direct

possible transfer

situations.

Metasynthesis 3:

Nurses are more

decisive and

confident when a

"plan" is in place;

INTERACT is a

quality

improvement

program designed

to reduce

hospitalizations

Eleven

interventions to

reduce hospital

admissions from

nursing homes

were identified.

Several of the

interventions had

For future studies

evaluating

interventions to

reduce

rehospitalizations,

adherence to the

framework of

complex

effects on reducing interventions is

hospital admissions recommended.

and may represent

important aspects

of nursing home

care to reduce

hospital

admissions.

Assessment tools Further research is differed widely

regarding the needed to develop a tool that is aspects considered evidence-based,

as criteria for

judgement of comprehensive, and generaliz able to

appropriateness of different regions or acute care countries in order to assess the admissions. All

appropriateness of hospital admission the systematic among skilled

review were nursing facility $\begin{array}{ll}\text { developed based on } & \text { nursing faciling } \\ \text { expert opinion. } & \text { residents. }\end{array}$

$\begin{array}{ll}\text { Measures overlap } & \text { Long Term Quality } \\ \text { and are highly } & \text { Alliance (LTQA) } \\ \text { detailed; failure of } & \text { should define } \\ \text { measures to } & \text { measures in general; } \\ \text { account for medical } & \text { the LTQA should }\end{array}$


hospitalizations was

conducted.

\section{Ouslander,}

Naharci,

\&Engstrom,

Shutes, Wolf,

Alpert, Rojido,

Tappen, \&

Newman, 2011

Data and lessons
learned from more
than 4800 hospital
transfers from 64
skilled nursing
facilities who trialed
INTERACT QI
program

SNFs were

recruited via contacts from national organizations. A total of 613 SNFs were screened for eligibility via online and telephone surveys. services and

supports
Inclusion criteria:

Evidence of

support from

corporate and

facility leadership;

ability to manage

acute changes in

condition safely

within the facility

as evidenced by

availability of lab,

pharmacy, \&

medical care

resources

Exclusion criteria:

Hospital-based

facilities;

participating in

another project

design specifically

to reduce acute care

transfers or

hospitalization

rates that might

influence the

intervention or

control conditions;

conducting more comorbidities and define as specifically

clinical complexity; as possible the

failure of measures population of frail

to account for and chronically ill

differences in the adults who receive

available resources long-term care

for care in services to test

particular facilities validity of measures

and other care

intended to reduce

settings; lack of potentially

research to validate preventable

measures for use in hospitalizations;

the chronically ill the LTQA should

adults who receive identify ways to help

long-term care

clinicians

services; lack of

attention to how

and where

understand current

and new programs;

several interventions

decisions about

hospitalization are

made for the adult

for nursing staff at

receiving long-term

nursing homes

described in this

care and supports;

the extent of

paper include

training and structure procedures

current and future

effort to reduce

potentially

in determining

preventable

potentially

preventable

hospitalizations by

government

programs is

growing

Interim analysis of More than one

approximately half quarter of the

of the QI tools was transfers were

performed in the

middle of the

recognized by the

staff as potentially

implementation

period. The mean

and median

avoidable.

hospitalizations

numbers were 76

and 49 , with an

interquartile range

INTERACT may

help prevent

unnecessary

hospitalizations.

of $30-106$. The

results of the

analysis of all the

QI tools in the

article are almost

identical to the

interim analysis.
SNF staff should be trained in comprehensive acute changes more than disease specific. Templates for the evaluation of acute changes in SNF clients and related decision support tools should account for the common occurrence of multiple and nonspecific symptoms in the SNF population. 
than one other

major quality

improvement or

research project

during the project

period

Boutwell \&

Hwu, 2009
Review the evidence Survey of published Inclusion: for effective interventions to reduce hospitalizations across patient populations and settings of care literature in epidemiology of

PubMed; search avoidable

strategies narrowed hospitalizations

by publication date and

(few than 10 years rehospitalizations

from September from specific

2008); English, and setting of care,

U.S. based studies specific service interventions,

interventions for

patients with

specific diseases
158 articles were Researchers and Nurse-led transition selected by the institutions are care that proved to research team for attempting to be effective further review, The identify strategies interventions Institute for to reduce avoidable include the Hospital hospitalizations; following: Improvement improvement in communication conducted the reducing tools, patient analysis.

rehospitalizations is activation, nurse-led possible although coaching, education the relative effect of sessions, telephone any single outreach, intervention discussed in this document is not possible at this comprehensive discharge planning and home follow-up visits time; many of the interventions in literature to date have focused on heart failure populations; a variety of approaches seem to be promising

\section{Appendix C. Summary of Primary Research Evidence}

\begin{tabular}{ll}
\hline Citation & $\begin{array}{l}\text { Question or } \\
\text { Hypothesis }\end{array}$ \\
$\begin{array}{l}\text { Rantz, Flesner, } \\
\text { Franklin, Galambos, } \\
\text { Pudlowski, Pritchett, }\end{array}$ & $\begin{array}{l}\text { This study explores } \\
\text { staff perceptions in a } \\
\text { nursing home that } \\
\text { Alexander, }\end{array}$ \\
\&Lueckenotte, 2015 & $\begin{array}{l}\text { key project goals of } \\
\text { Missouri Quality } \\
\text { Initiative intervention } \\
\text { (MOQI). }\end{array}$
\end{tabular}

Abrahamson, Mueller, What are the

Open System model

Davila, \&Arling, 2014 O

\section{Theoretical Foundation}

Not indicated

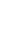
nursing staff when organizational efforts are made to reduce hospital transfers? How does the role of the nurse as structure

of

\section{Research Design (include tools) and Sample Size}

Single facility case study using quantitative and qualitative measures

\begin{tabular}{|c|c|c|c|}
\hline & & $\begin{array}{l}\text { INTERACT } \\
\text { assessment tools are } \\
\text { important parts of } \\
\text { MOQI. Clinical skills } \\
\text { of nursing staff } \\
\text { improved. }\end{array}$ & achieved. \\
\hline $\begin{array}{l}\text { pen System model } \\
\text { organizational } \\
\text { ructure }\end{array}$ & $\begin{array}{l}\text { Semi-structured } \\
\text { qualitative interviews; } \\
\text { PIPP evaluation; sample } \\
\text { size } 76 \text { RNs and LPNs } \\
\text { within } 38 \text { of the } 46 \\
\text { nursing home } \\
\text { participating in a QI } \\
\text { effort. IRB approval }\end{array}$ & $\begin{array}{l}\text { Five themes emerged } \\
\text { from the data: 1) } \\
\text { negotiating the } \\
\text { hospitalization } \\
\text { decision, 2) } \\
\text { increased nurse } \\
\text { confidence, 3) } \\
\text { working inside the }\end{array}$ & $\begin{array}{l}\text { Further hospitalization } \\
\text { reduction efforts } \\
\text { would benefit from } \\
\text { interventions that seek } \\
\text { to reduce the barriers } \\
\text { that emerge when } \\
\text { nurses are in the } \\
\text { position to span the }\end{array}$ \\
\hline
\end{tabular}

\section{Recommendations and Implications}

Key implementation MOQI goals. The findings can help
facility has decreased guide others as they use of antipsychotic find ways to medications. accomplish goals. Education was Reducing unnecessary identified as a theme hospitalizations of in reducing hospital in reducing nursing home residents can be INTERACT 
boundary-spanner

within an open

organizational system

influence the nursing

staff experience?
The Center for Health The study was Workforce Studies, 2014

Lamb, Tappen, Diaz, $\quad$ To describe nursing Herndon \& Ouslander, staff perceptions of 2011 avoidability of hospital transfers of nursing home clients
Not indicated

Not indicated

Qualitative research using case study methodology; convenience sampling; semi-structured interviews. Sample size was 30 telephone and face-to-face interviews from five hospitals and six nursing homes.

Mixed methods qualitative and quantitative analysis of 1347 QI review tools completed by staff at 26 nursing home and transcripts of conference calls; an interprofessional team coded and quantified reasons for hospital transfer on 1347 QI review tools; participan were site coordinators and staff

Ouslander, Lamb, Tappen, Herndon, Diaz, Roos,

Does the use of INTERACT II collaborative project Grabowski, \& Bonner, reduce hospitalizations 2011

The INTERACT conducted as a quality improvement project. boundary, and 4) working within a boundary between the nursing home and system. Findings are outside stakeholders. consistent with the is idea that licensed nursing staff are in an organizational role that requires them to negotiate the boundary between multiple internal and external stakeholders to influence the hospitalization decision.

Interview

Staff education is

participants said the fundamental in efforts more the healthcare to reduce rates of workforces know about the transition process goals, the more they can do to effect positive outcomes. Training "from the bottom up and from the top down" was emphasized. Nursing home staff rated fewer hospital transfers as avoidable then published estimates. Nursing homes that were more engaged in INTERACT submitted the majority of QI review tools. The percentage of stransfers rated avoidable and possibly avoidable was significant at the 0.05 level. $17 \%$ reduction in self-reported intervention was Descriptive data were collected on participating nursing homes at project initiation and completion using the Online Survey and Certification and hospital admissions from the same 6-month period the year before; a group of 17 of those avoidable hospitalizations. The INTERACT QI program encourages training of staff.

Findings related to the level of engagement of the nursing home with INTERACT may provide useful insights into the process associated with changing perspectives about avoidability in nursing home staff. Future QI initiatives to reduce potentially avoidable acute care transfers from nursing homes will need to be conducted to be effective. INTERACT should be further evaluated in RCTs to determine its effect on avoidable hospitalizations and their related morbidity and cost. Results are nursing homes had a encouraging. $24 \%$ reduction, compared with $6 \%$ in the group who was not as engaged.
Reporting (OSCAR) file and Nursing Home

Compare; 25 nursing homes in 3 states 


\section{Appendix D. INTERACT Stop and Watch Early Warning Tool}

\section{Stop and Watch Early Warning Tool}

If you have identified a change while caring for or observing a resident, please circle the change and notify a nurse. Either give the nurse a copy of this tool or review it with her/him as soon as you can.

\begin{tabular}{l|l|l}
\hline S & Seems different than usual \\
T & Talks or communicates less \\
P & Overall needs more help \\
P & Pain - new or worsening; Participated less in activities \\
a & Ate less \\
n & No bowel movement in 3 days; or diarrhea \\
d & Drank less \\
W & Weight change \\
A & Agitated or nervous more than usual \\
T & Tired, weak, confused, or drowsy \\
C & Change in skin color or condition \\
H & Help with walking, transferring, toileting more than usual \\
\hline Patient/Resident & \\
\hline Your Name Check here if no change noted \\
while monitoring high risk patient
\end{tabular}

\section{Appendix E. INTERACT Change of Condition Card Sample}

\begin{tabular}{|c|c|c|}
\hline Symptom or Sign & Immediate & Non-Immediate \\
\hline Abdominal Pain ${ }^{1}$ & $\begin{array}{l}\text { Abrupt onset severe pain or distention, OR } \\
\text { with fever, vomiting }\end{array}$ & $\begin{array}{l}\text { Mild diffuse or localized pain, unrelieved by antacids or } \\
\text { laxatives }\end{array}$ \\
\hline Abdominal Distention ${ }^{1}$ & $\begin{array}{l}\text { Rapid onset, OR presence of marked tenderness, fever, } \\
\text { vomiting, GI bleeding }\end{array}$ & $\begin{array}{l}\text { Progressive or persistent distension not associated with } \\
\text { symptoms }\end{array}$ \\
\hline $\begin{array}{l}\text { Abdominal Tenderness }{ }^{1} \\
\text { (e.g., bloating, cramps, etc...) }\end{array}$ & $\begin{array}{l}\text { Associated with fever, continuous GI bleeding, or other acute } \\
\text { symptoms }\end{array}$ & $\begin{array}{l}\text { Persistent discomfort not associated with other acute } \\
\text { symptoms }\end{array}$ \\
\hline Abrasion & Accompanied by significant pain or bleeding & $\begin{array}{l}\text { If bleeding continues or if associated with evidence of } \\
\text { local infection }\end{array}$ \\
\hline Agitation $^{2}$ & $\begin{array}{l}\text { Abrupt onset of significant change from usual, OR } \\
\text { associated with fever or new onset abnormal neurological signs }\end{array}$ & Continued progression or persistence of symptoms \\
\hline Altered Mental Status & $\begin{array}{l}\text { Abrupt significant change in cognitive function from usual } \\
\text { with or without altered level of consciousness }\end{array}$ & $\begin{array}{l}\text { Persistent change from usual cognitive function } \\
\text { with no other criteria met for immediate notification }\end{array}$ \\
\hline Appetite, Diminished & No oral intake 2 consecutive meals & $\begin{array}{l}\text { Significant decline in food and fluid intake in resident } \\
\text { with marginal hydration and nutritional status }\end{array}$ \\
\hline Asthma & Acute episode with wheezing, dyspnea, or respiratory distress & $\begin{array}{l}\text { Self-limited episode that was more extensive or less } \\
\text { responsive to treatment than the usual }\end{array}$ \\
\hline
\end{tabular}

